\title{
A Methodology to Develop a Distribution Transformer Model for Transient Studies
}

\author{
W.D.A.S. Wijayapala, J.R. Lucas and L.S. Hasthanayake
}

\begin{abstract}
Transformers are some of the expensive components of a distribution network. Records from the Ceylon Electricity Board (CEB) indicate that a considerable number of failures of these transformers are caused by lightning surges. Transformer failures incur huge costs to utility suppliers like CEB.

Thus the behaviour of distribution transformers under transient conditions needs to be studied and for this a transformer model is very much essential. With the help of such a model, the behaviour of distribution transformers when subjected to lightning surges can be studied.

In this paper, a methodology is presented to develop a model to represent a distribution transformer under transient conditions. The validation of the model is illustrated by the calculation of parameters based on a $160 \mathrm{kVA}, 33 / 0.415 \mathrm{kV}$, three phase distribution transformer. The model is simulated using PSCAD software and the output is obtained when the standard lightning waveform and chopped surge waveforms are input to the model. In order to validate the developed model, the output voltage distribution along the transformer winding is observed and compared with the results of an experiment presented in a research publication [7].
\end{abstract}

Key words: Distribution Transformer, Modelling, PSCAD, Lightning, Transient Studies

\section{Introduction}

When they are being operated, distribution transformers undergo transient conditions which are different from their normal conditions operating at the standard frequency $(50 \mathrm{~Hz})$. Lightning and switching operations in the network are possible causes for these transients. Distribution transformers are designed to function at $50 \mathrm{~Hz}$ but when they are subjected to voltage surges, the behaviour of the windings becomes remarkably different.

This is mostly because voltage surges due to the shape of the surge waveform, can contain many high frequency components besides the fundamental frequency. The short rise time causing a high rate of rise of an impulse can cause deterioration of the insulation of the transformer winding leading ultimately to a dielectric breakdown. The insulation of the transformer winding gets stressed when surges impinge on the transformer. This stress needs to be considered in the design stage of the transformer. Therefore, modelling the transformer winding for such frequencies is important.

The main objective of this paper is to propose a transformer model for transient studies in distribution lines. By using the proposed model, it is possible to obtain the surge voltage distribution along the winding. In order to achieve this objective, the following methodology was formulated.

\section{Methodology}

- Identifying the winding structure of the distribution transformers

- Determining the transformer winding parameters

- Developing the model

- Validating the model

\section{Transformer Winding Parameters}

A commonly used $160 \mathrm{kVA}, 33 / 0.415 \mathrm{kV}$ (delta/star) three phase distribution transformer was used to illustrate the findings of the study. Sri Lankan distribution system is a TT system. Therefore, the primary side (HV side) of the distribution transformer is delta connected and the secondary side (LV side) is star connected with a grounded neutral.

The transformer tank and the surge arrestors at the delta connected side are grounded separately [1].

Eng.W.D.A.S.Wijayapala, BSc Eng (Hons)
(Moratuwa), MEng(Moratuwa), Int.PEng(SL), CEng,
FIE(Sri Lanka), MIEEE, Senior Lecturer, Department of
Electrical Engineering, University of Moratuwa.
Eng.(Prof.) J.R.Lucas, BSc Eng (Hons) (Cey),
MSc(Manch), Phd(Manch),FIEE,CEng, FIE(Sri Lanka),
Int.PEng(SL), Emeritus Professor, Department of
Electrical Engineering, University of Moratuwa.
Eng. L.S.Hasthanayake, Bsc Eng (Hons) (Moratuwa),
AMIE(Sri Lanka), Electrical Engineer(System Control
Centre Modernisation Project), Ceylon Electricity Board.


LV windings of a transformer consist of copper foils which are wound on top of the transformer core with the HV copper windings wound over the LV windings. There is a HV-LV barrier which provides the insulation between the LV and HV windings. This HV-LV barrier of about $20 \mathrm{~mm}$ thickness consists of two zigzag oil-impregnated pressboard insulation separated by a cylindrical pressboard of $1 \mathrm{~mm}$ thickness. Transformer oil is circulated through the space within the zig-zag pressboard [2]. Between the $\mathrm{HV}$ winding and the ground, the insulation is almost purely transformer oil whereas between LV winding and the core, a pressboard is inserted in addition to transformer oil.

\subsection{Winding Inductance and Resistance}

Transformer parameters such as winding resistances and inductances are calculated from full load and no-load test reports obtained from Lanka Transformers (Pvt) Limited [2].

\section{Open Circuit Test}

The Open Circuit Test determines the parameters of the shunt branch of the equivalent circuit. Under no-load conditions, the power input to the transformer virtually equals the core loss. If $\mathrm{I}_{0}$ and $\mathrm{P}_{\mathrm{i}}$ are the current and input power drawn respectively by the transformer on no load at rated voltage $V_{1}$ then;

$$
\begin{aligned}
& \cos \xi=\frac{P_{i}}{\sqrt{3} \cdot V_{1} \cdot I_{0}} \\
& I_{c}=I_{0} \cos \xi \\
& I_{m}=I_{0} \sin \xi
\end{aligned}
$$

where $\xi, I_{0}, I_{c}, I_{m}$, are usual no load parameters.

Thus the core loss resistance $R_{c}$, and the magnetising reactance $X_{m}$ are determined as,

$$
\begin{aligned}
& R_{c}=\frac{V_{1}}{I_{c}}, \\
& X_{m}=\frac{V_{1}}{I_{m}}
\end{aligned}
$$

and the equivalent circuit is shown in Figure 1.

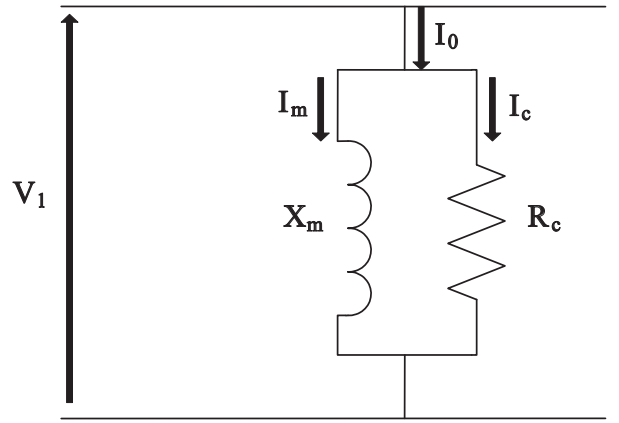

Figure 1 - Transformer Equivalent Circuit on Open Circuit

\section{Short Circuit Test}

A Short Circuit Test is performed to measure the full load loss $\left(\mathrm{P}_{\mathrm{c}}\right)$ and leakage impedance of a transformer. The voltage required to be applied to circulate the rated current $\left(\mathrm{I}_{2} /\right)$ on short circuit is called the impedance voltage $\left(\mathrm{V}_{\mathrm{sc}}\right)$ of the transformer.

The total leakage reactance and the total winding resistance are thus calculated as

$$
\begin{aligned}
& \left(X_{1}+X_{2}{ }^{\prime}\right)=Z_{s c} \cdot \sin \theta \\
& \left(R_{1}+R_{2}{ }^{\prime}\right)=Z_{s c} \cdot \cos \theta
\end{aligned}
$$

Note: The symbol " ' " is used to denote secondary quantities when referred to the primary side.

The equivalent circuit is given in Figure 2.

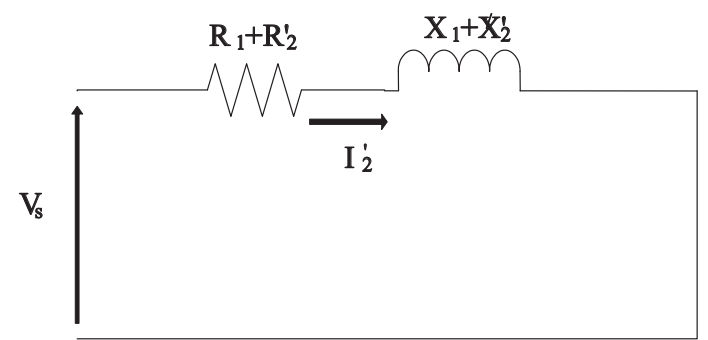

Figure 2 - Transformer Equivalent Circuit on Short Circuit

\subsection{Winding Capacitances}

The capacitances of the transformer windings are,

- $\mathrm{C}_{\mathrm{tt}}$ - Turn-to-turn capacitance of HV winding

- $\mathrm{C}_{11}$ - Layer-to-layer capacitance of HV winding

- $\mathrm{Cg}$ - Capacitance to ground (i.e. to tank and core) 


\section{Turn-to-Turn Capacitance, $\left(\mathrm{C}_{\mathrm{Ht}}\right)$}

The capacitance between adjacent turns, $\left(\mathrm{C}_{\mathrm{tt}}\right)$ is calculated using the following formula [3].

$C_{t t}=\varepsilon_{e q} \cdot \theta^{*} \cdot e^{\left(d_{c} / d_{i}\right)}+\varepsilon_{0} \cot \left(\frac{\theta^{*}}{2}\right)-\varepsilon_{0} \cot \left(\frac{\pi}{12}\right)$

where,

$$
\begin{aligned}
\theta^{*}= & \cos ^{-1}\left(1-\frac{1}{\varepsilon_{e q}} \ln \left(\frac{d_{e}}{d_{i}}\right)\right) \\
\varepsilon_{0}= & \text { Permittivity of air } \\
\varepsilon_{\mathrm{eq}}= & \text { Relative permittivity of insulation } \\
& \text { material } \\
\mathrm{d}_{\mathrm{e}}= & \text { External wire diameter } \\
\mathrm{d}_{\mathrm{i}}= & \text { Internal wire diameter } \\
\mathrm{n}_{\mathrm{t}} \quad & \text { Number of turns per layer of the } \\
& \text { winding }
\end{aligned}
$$

The total series capacitance of a layer of the winding $\left(\mathrm{C}_{\mathrm{tt}} /\right)$ is,

$$
C_{t t}=\frac{C_{t t}}{n_{t}-1}
$$

\section{$\mathrm{C}_{l l}$ - Layer-to-Layer Capacitance}

The capacitance between two layers of the HV winding $\mathrm{C}_{l l}$ can be calculated as follows [3].

$$
C_{l l}=\frac{n_{t}\left(n_{t}+1\right)\left(2 n_{t}+1\right)}{6 n_{t}^{2}} \cdot 1 . C_{t t}
$$

where,

$$
\begin{aligned}
& n_{t}=\text { Number of turns per layer } \\
& l=\text { Average length of a turn } \\
& C_{t t}=\text { Turn-to-turn capacitance }
\end{aligned}
$$

The winding structure can be modelled as a coaxial cylindrical capacitor, or as a parallel plate capacitor if the curvature radius $r$ is large [1].

$$
\mathrm{C}_{l l}=\frac{\epsilon_{0} \cdot \epsilon_{\mathrm{r}} 2 \prod \mathrm{rw}}{\mathrm{d}}
$$

where,

$$
\begin{aligned}
& \mathrm{d} \text { - Distance between two wires of } \\
& \text { different layers } \\
& \mathrm{r} \text { - Curvature radius } \\
& \mathrm{w} \text { - Height of the winding }
\end{aligned}
$$

Capacitance to Ground, $\left(\mathrm{C}_{\mathrm{g}}\right)$

The capacitance to ground includes both the capacitance between the winding and the transformer tank and the capacitance between the winding and the core.

The capacitance $C_{g t}$ between an end phase winding and the transformer tank, is calculated using $\mathrm{m}$ the following equation [4],

$$
C_{g t}=0.75 \cdot \frac{2 \pi \varepsilon_{0} \varepsilon_{r} h^{\prime}}{\ln \left(t / d_{0}\right)}
$$

where,

$$
\begin{aligned}
h^{\prime} & =h+d \\
h & =\text { Height of the winding } \\
d_{o} & =\text { Outer diameter of the inner winding } \\
d_{i} & =\text { Inner diameter of the outer winding } \\
d & =\text { Gap between two layers } \\
t & =\text { Internal width of the tank }
\end{aligned}
$$

The HV winding is wound on the HV-LV barrier insulation which in turn is wound on the copper foils of the LV winding. The capacitance of the HV-LV barrier, $\mathrm{C}_{\mathrm{HV}-\mathrm{LV}}$ and the capacitance between the two LV winding turns can be calculated using the following formulae [4].

$$
\begin{gathered}
C_{H V-L V}=\frac{2 \pi \varepsilon_{0} \varepsilon_{r} h}{\ln \left(d_{i} / d_{0}\right)} \\
C_{L V-t t}=\frac{2 \pi \varepsilon_{0} \varepsilon_{r} h}{\ln \left(d_{i} / d_{0}\right)}
\end{gathered}
$$

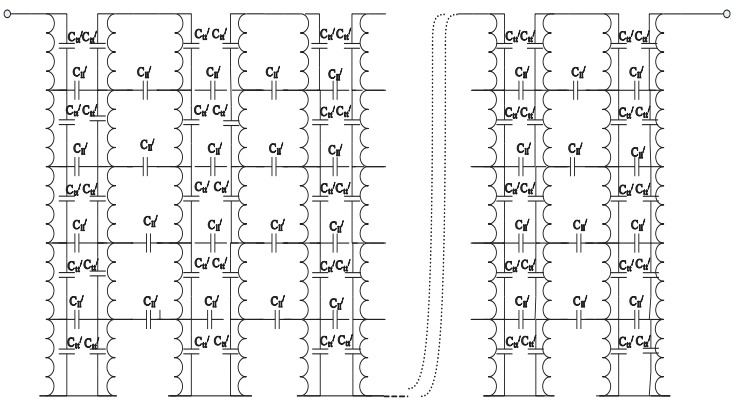

Figure 3 - Capacitances along the HV Winding

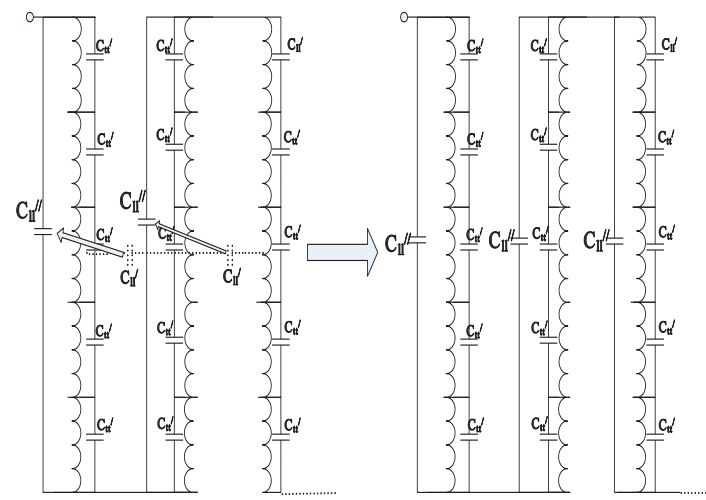

Figure 4 - Transferring the layer-to-layer capacitances to capacitances along the HV Winding

Since both $\mathrm{C}_{\mathrm{tt}}{ }^{\prime}$ and $\mathrm{C}_{l l}$ " are in parallel, the resultant capacitance would be the summation 
of them, i.e. $C_{\text {resultant }}=\mathrm{C}_{t t}{ }^{\prime}+\mathrm{C}_{\mathrm{ll}}$ ". Therefore, in this study, the resultant capacitance parallel to the winding layer is taken as only $\mathrm{C}_{l l}$ " since the value of $\mathrm{C}_{\mathrm{tt}}{ }^{\prime}$ is very small compared to $\mathrm{C}_{\mathrm{ll}}$ ".

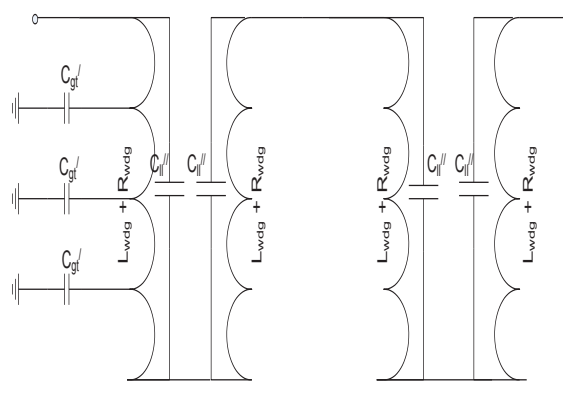

Figure 5 - Capacitances, inductances and resistances along the winding

\subsection{The Proposed Transformer Model}

Once the values of the inductance per layer, transferred layer-to-layer capacitance parallel to the layer and capacitance to ground are calculated, the transformer model shown in Figure 6 can be developed. The first layer (outer most layer) of the winding is divided into two halves and the corresponding values of inductances and capacitances are calculated as appropriate.
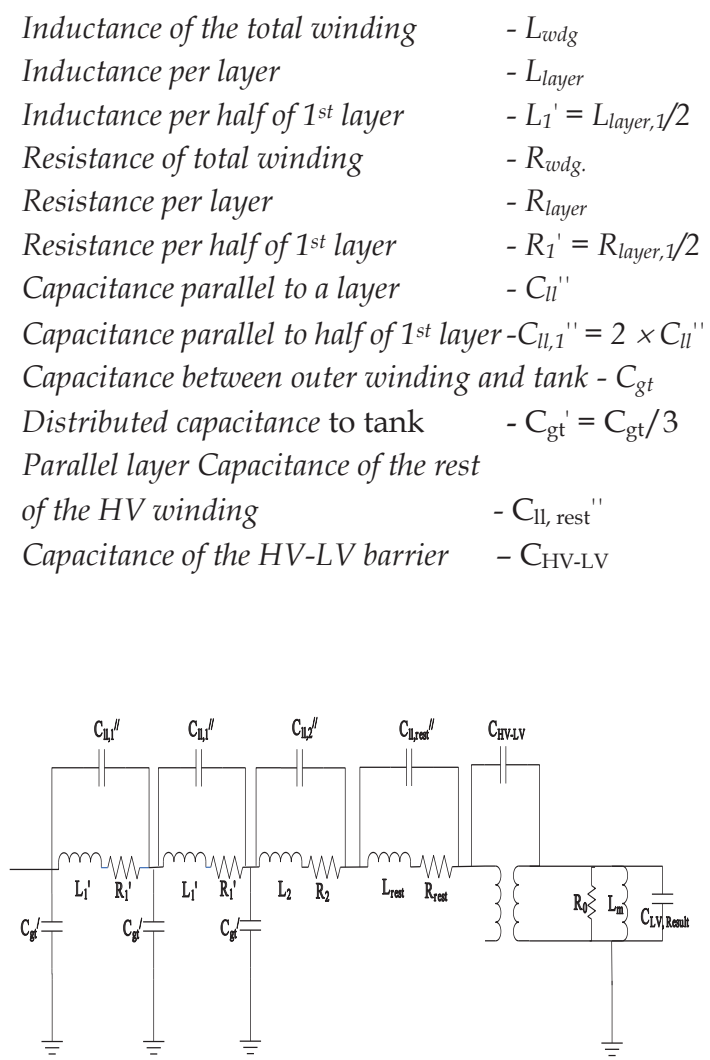

Figure 6 - Proposed per-phase Distribution Transformer Model
Table 1 gives the values of the parameters of the model for the $160 \mathrm{kVA}, 33 / 0.415 \mathrm{kV}$ distribution transformer given in Figure 6. In this model after the first two layers, the rest of the winding is represented by lumped values of inductances, capacitances and resistances.

Table 1 - Parameters of the Proposed Model

\begin{tabular}{|c|c|c|c|c|}
\hline Parameter & $\mathrm{L}_{1} /(\mathrm{H})$ & $\mathrm{L}_{2}(\mathrm{H})$ & Lrest (H) & $\begin{array}{l}\mathrm{C}_{11,1 / 1} \\
(\mathrm{pF})\end{array}$ \\
\hline Value & 0.045 & 0.156 & 2.343 & 48.23 \\
\hline Parameter & $\mathrm{C}_{11,2} / /(\mathrm{pF})$ & $\left.\mathrm{C}_{11, \mathrm{res}} \mathrm{l} / \mathrm{pF}\right)$ & $R_{0}(\Omega)$ & $\mathrm{R}_{1} /(\Omega)$ \\
\hline Value & 36.293 & 3.20 & 439.31 & 5.39 \\
\hline Parameter & $R_{2}(\Omega)$ & $R_{\text {rest }}(\boldsymbol{\Omega})$ & $\mathrm{Cgt}_{\mathrm{gt}}(\mathrm{pF})$ & $\begin{array}{c}C_{\text {HVLV }} \\
(\mathrm{pF})\end{array}$ \\
\hline Value & 18.55 & 278.32 & 27.38 & 238.7 \\
\hline Parameter & $\begin{array}{c}C_{L V, \text { result }} \\
\text { (pF) }\end{array}$ & $\mathrm{L}_{\mathrm{m}}(\mathrm{H})$ & & \\
\hline Value & $2,022.84$ & 1.04 & & \\
\hline
\end{tabular}

\section{Simulation Results of the Model}

The proposed transformer model is simulated using PSCAD software. The purpose of the study is to show as to what takes place within the transformer winding under the impact of the standard lightning waveform. Figure 6 shows the per-phase distribution transformer model. The per-phase distribution transformer model is arranged as shown in Figure 7 and simulated using PSCAD software. In the arrangement shown in Figure 7, the three phases of the distribution transformer are considered and standard lightning surge is input to one phase as shown.

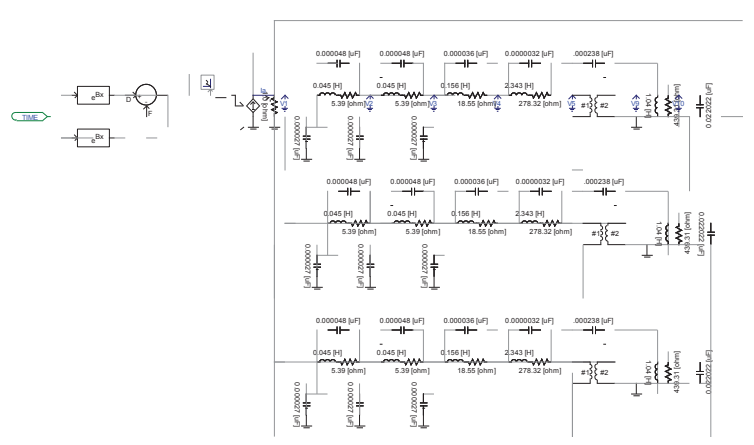

Figure 7 - Transformer Model simulated using PSCAD

The surge enters the winding from the line end of the HV winding leading to the distribution of an impulse voltage along the winding. In the case of steep-fronted transients, this distribution is not uniform and a large portion of the applied voltage is usually concentrated on the first few turns of the winding [5]. Therefore in the simulations, 
more attention has been paid to the first layer (outermost layer) of the HV winding.

Although the phenomena which we are dealing with takes only a very small fraction of a second, it is nevertheless convenient to divide it into three distinct time periods, each requiring separate treatment. They are the initial period, transient period, and final period.

The initial period is the period from the beginning of the disturbance to the time of maximum applied voltage. The time involved is so small that there is no appreciable growth of magnetic flux and therefore without an appreciable error the phenomena may be considered as entirely electrostatic [5][6]. If the three phases of the $\mathrm{HV}$ winding of the transformer are named as Phase A, Phase B, and Phase $C$, the surge will enter from Phase A as shown in Figure 7.

\subsection{Validation of the Model}

The surge voltage distribution along the outermost layer of the transformer winding can be observed through simulation using PSCAD. The standard lightning surge waveform $(1.2 / 50 \mu \mathrm{s})$ is input to the proposed model in the simulation and the voltage along the first layer (outermost) of the HV winding is observed as the output.

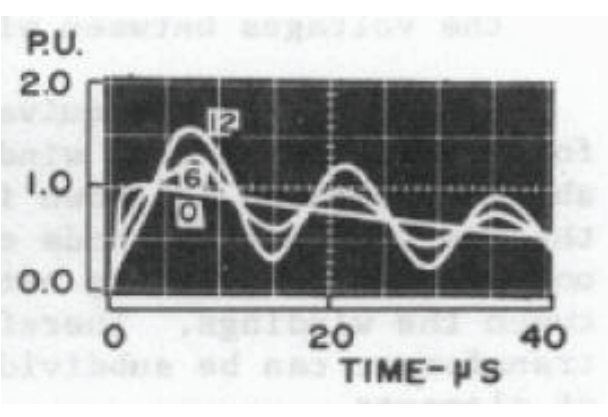

Figure 8 - Experimentally observed results of a similar type of transformer [7]

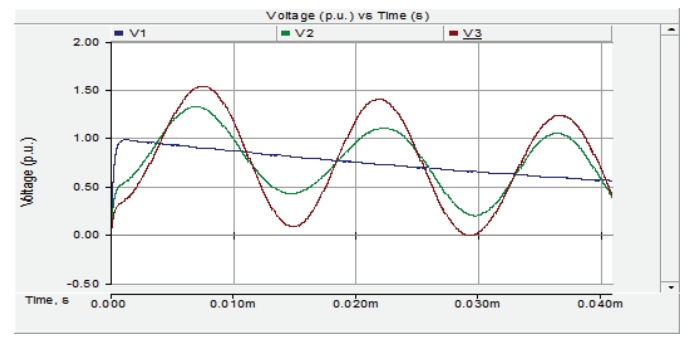

Figure 9 - Simulated Output of the Proposed Model
The validation of the model is done by comparing simulation results of the proposed model with experimental results presented for a similar type of transformer in a research paper [7] shown in Figure 8.

In Figure $8, " 0$ ", "6", and " 12 " are waveforms at the input, middle and end of the outermost layer of the winding respectively.

In Figure 9, $V_{2}$ is the voltage waveform at the midpoint of the outermost layer of the HV winding and $\mathrm{V}_{3}$ is the voltage waveform at the end of the outermost layer. Since there are 183 turns in the outermost $\mathrm{HV}$ winding layer, $\mathrm{V}_{3}$ corresponds to the voltage waveform of the $183^{\text {rd }}$ turn.

For the comparison of the two waveforms, the peak value of the first positive cycle, time to first peak, and the peak value of the second positive cycle of the voltage waveforms at the midpoint $\left(\mathrm{V}_{2}\right.$ \& "6") and at the end $\left(\mathrm{V}_{3} \&\right.$ " 12 ") of the outermost layer are used. The peak value of the first positive cycle represents the maximum amplitude. The time to first peak provides an idea of the approximate voltage gradient whereas the peak value of the second positive cycle implies the attenuation rate.

Table 2 shows the comparison of the experimental and simulation results of the model.

Table 2 - Comparison of Experimental and Simulated Results

\begin{tabular}{|c|c|c|c|c|c|c|}
\hline & \multicolumn{2}{|c|}{$\begin{array}{l}1^{\text {st }} \text { Peak } \\
\text { Value(p.u.) }\end{array}$} & \multicolumn{2}{|c|}{$\begin{array}{l}\text { Time to } 1^{\text {st }} \\
\text { Peak }(\mu \mathrm{s})\end{array}$} & \multicolumn{2}{|c|}{$\begin{array}{l}2^{\text {nd }} \text { Peak } \\
\text { Value (p.u.) }\end{array}$} \\
\hline & $\mathrm{V}_{2}$ & $\mathrm{~V}_{3}$ & $\mathrm{~V}_{2}$ & $\mathrm{~V}_{3}$ & $\mathrm{~V}_{2}$ & $\mathrm{~V}_{3}$ \\
\hline $\begin{array}{l}\text { Experimental } \\
\text { Results [7] }\end{array}$ & 1.38 & 1.6 & 7.4 & 7.83 & 1.06 & 1.325 \\
\hline $\begin{array}{l}\text { Simulated } \\
\text { Results }\end{array}$ & 1.38 & 1.6 & 6.96 & 7.83 & 1.17 & 1.43 \\
\hline
\end{tabular}

Experimental results have been obtained from the work of "A.Miki, T.Hosoya, and K.Okuyama" [7] while simulated results have been obtained from the current study. It can be seen from Table 2 that the maximum amplitude and the voltage gradient of both the simulated output waveforms and the experimental results are almost the same. The peak values of the second positive cycle of the simulated waveforms are slightly higher than that of the experimentally observed waveforms but the deviation is only within $10 \%$ of the experimental value. In general, there exists good correlation between the 
shapes of the simulated and measured surge distributions. Therefore, it is seen that the proposed model is capable of finding the transient voltage distribution along the transformer winding with a reasonable degree of accuracy.

\subsection{Output of the Model}

\subsubsection{Output Waveforms when the Full Surge Wave is Input}

The simulated outputs of the model along the first (outer most) layer of Phase A of the HV winding of the transformer when the surge enters from the same phase, are shown in Figures 10 to 16 for different durations of simulations.

Figure 10 shows the voltage waveforms at the beginning $\left(\mathrm{V}_{1}\right)$, at the middle $\left(\mathrm{V}_{2}\right)$ and at the end $\left(\mathrm{V}_{3}\right)$ of the outermost layer of the $\mathrm{HV}$ winding of the transformer up to $1.2 \mu \mathrm{s}$. Figure 11 shows the transient voltage distribution along the outermost layer of the winding up to $12 \mu \mathrm{s}$.

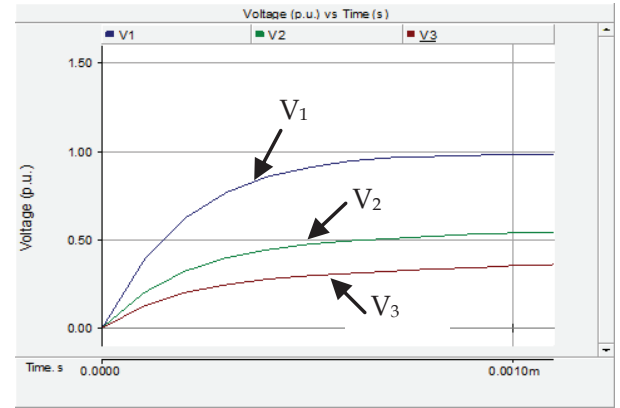

Figure 10 - Voltage distribution along the outermost layer of the HV Winding up to 1.2 $\mu \mathrm{s}$

The initial period of the phenomena when the effect of magnetic flux is negligible is shown in Figure 10. The effect of the magnetic flux can be seen in Figure 11 and it can be considered as the beginning of the transient period or the intermediate period of the phenomena.

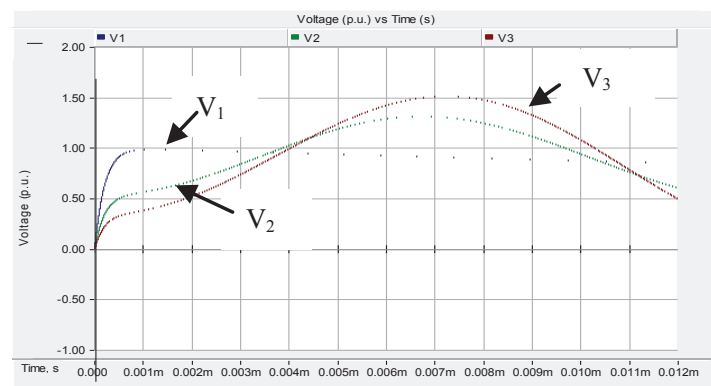

Figure 11 - Voltage distribution along the outermost layer of HV Winding up to $12 \mu \mathrm{s}$

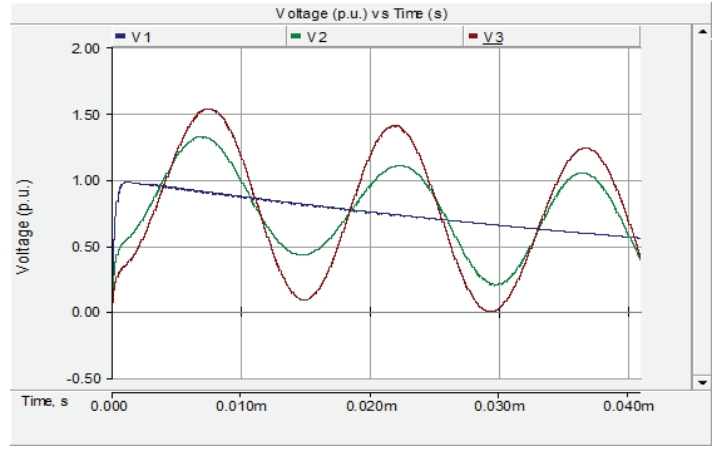

Figure 12 - Voltage distribution along the outermost layer of the HV Winding up to $40 \mu \mathrm{s}$

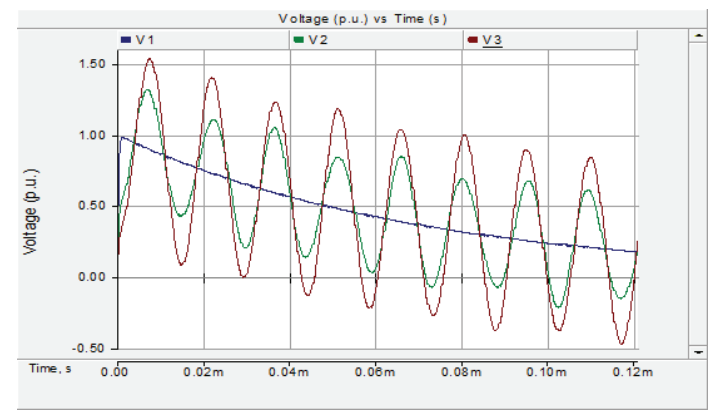

Figure 13 - Voltage distribution along the outermost layer of the HV Winding up to $0.12 \mathrm{~ms}$

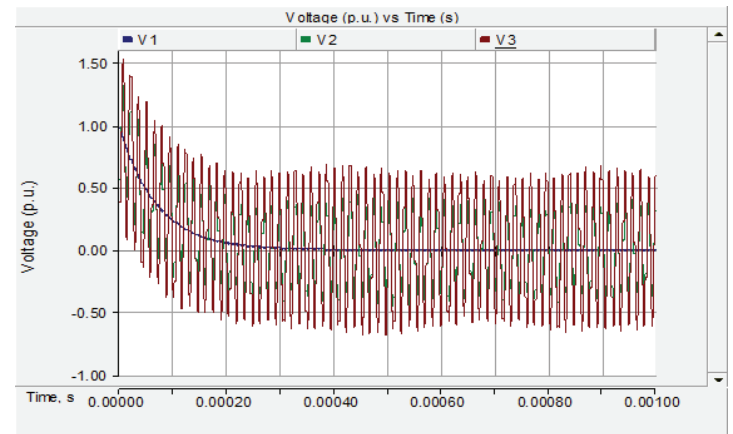

Figure 14 - Voltage distribution along the outermost layer of the HV Winding up to $1 \mathrm{~ms}$

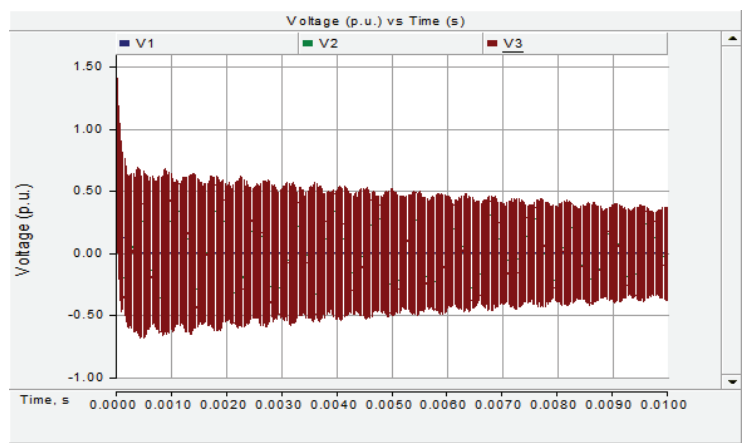

Figure 15 - Voltage distribution along the outermost layer of the HV Winding up to $10 \mathrm{~ms}$ 


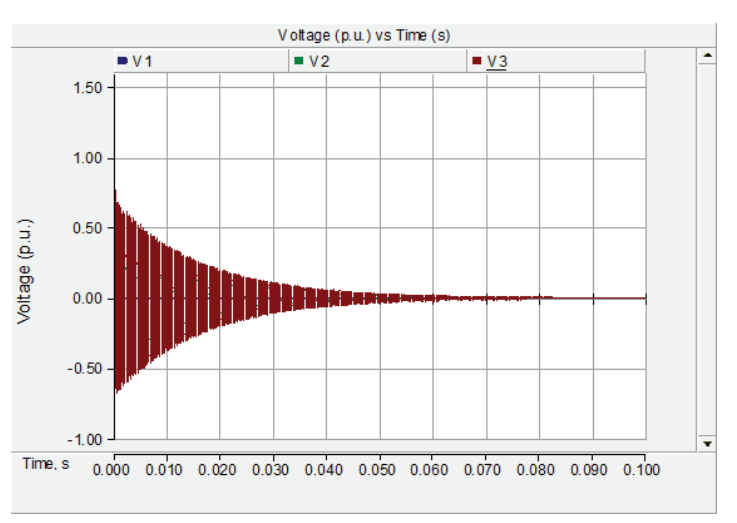

Figure 16 - Voltage distribution along the outermost layer of the HV Winding up to $100 \mathrm{~ms}$

From Figures 15 and 16 it is evident that the envelops of the voltage waveforms are decaying with time and the Figures show the final period of the phenomena when the voltage envelop has become almost zero.

\subsubsection{Output Waveforms when chopped Surge Waves are Input}

Distribution transformers are usually protected against lightning surges with surge arresters and arcing gaps. Due to the operation of these protective devices connected close to the HV bushings, chopped surge waves may appear at the line end of the HV winding of the transformer. To simulate this situation, surge waveforms chopped at $1 \mu \mathrm{s}, 2 \mu \mathrm{s}, 3 \mu \mathrm{s}$, $4 \mu \mathrm{s}$, and $5 \mu \mathrm{s}$ are input to the proposed model and the output observed.

The voltage distribution along the outermost layer of a phase winding when a surge wave chopped at $1 \mu$ s enters from the same phase winding is shown in Figure 17.

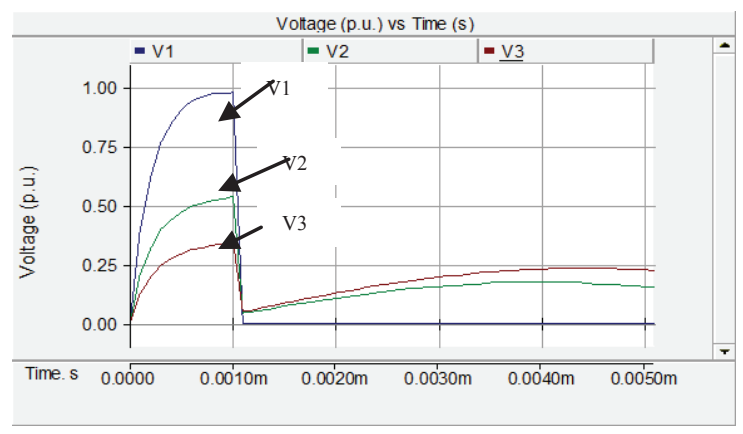

Figure 17 - Voltage distribution along the outermost layer of Phase A of the HV Winding when a surge wave chopped at $1 \mu \mathrm{s}$ is input to Phase A
Initial, intermediate and final states of the voltage waveforms along the outermost layer of a phase winding when a surge chopped at $2 \mu \mathrm{s}$ is input to the same phase winding, are shown in Figures 18, 19, 20, and 21.

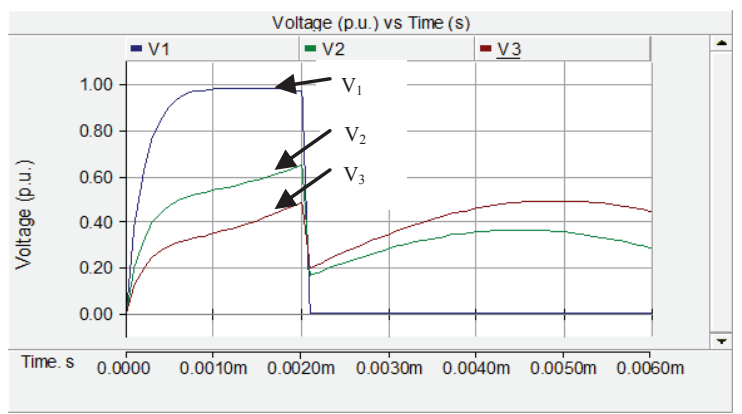

Figure 18 - Voltage distribution along the outermost layer of Phase A of the HV Winding when a surge wave chopped at $2 \mu \mathrm{s}$ is input to Phase A

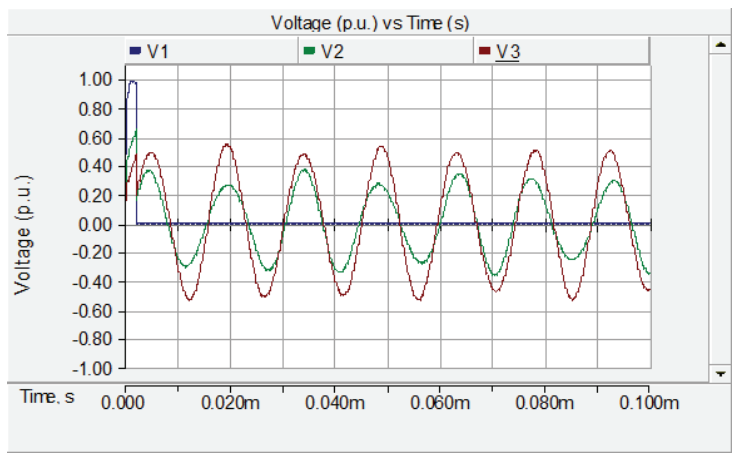

Figure 19 - Voltage distribution along the outermost layer of Phase A of the HV Winding when a surge wave chopped at $2 \mu \mathrm{s}$ is input to Phase A up to $0.1 \mathrm{~ms}$

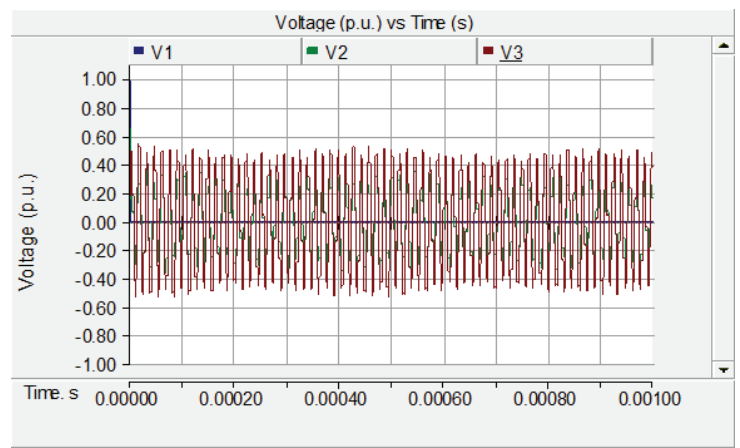

Figure 20 - Voltage distribution along the outermost layer of Phase A of the HV Winding when a surge wave chopped at $2 \mu \mathrm{s}$ is input to Phase A up to $1 \mathrm{~ms}$ 


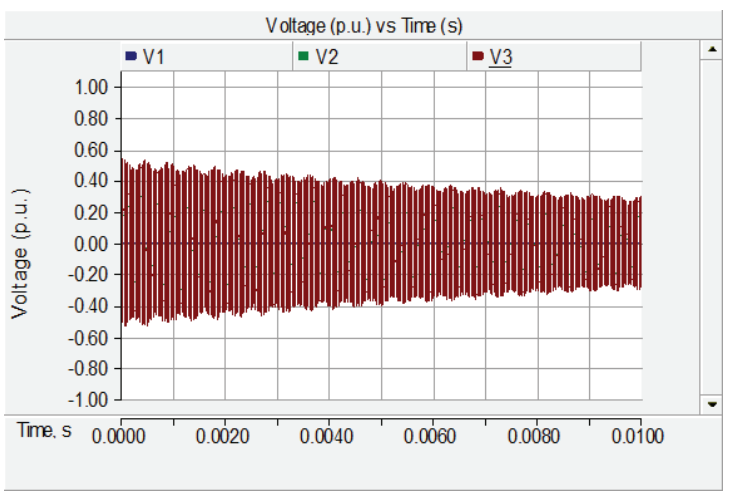

Figure 21 - Voltage distribution along the outermost layer of Phase A of the HV Winding when a surge wave chopped at $2 \mu \mathrm{s}$ is input to Phase A up to $10 \mathrm{~ms}$

By considering the peak values of voltage waveforms along the length of the transformer winding during the initial period $(0 \mu \mathrm{s}-1.2 \mu \mathrm{s})$, the graph shown in Figure 22 can be obtained which shows the initial impulse voltage distribution along the length of the HV phase winding. It can be seen that there is a sharp slope closer to the line end of the winding. The graph shown in Figure 23 is obtained by considering the peak values of waveforms along the two outermost layers. Figure 24 shows the impulse voltage distribution along the length of the two outermost layers during $1 \mu$ s to $10 \mu$ s time intervals when the full surge wave and the chopped surge waves are input to the model.

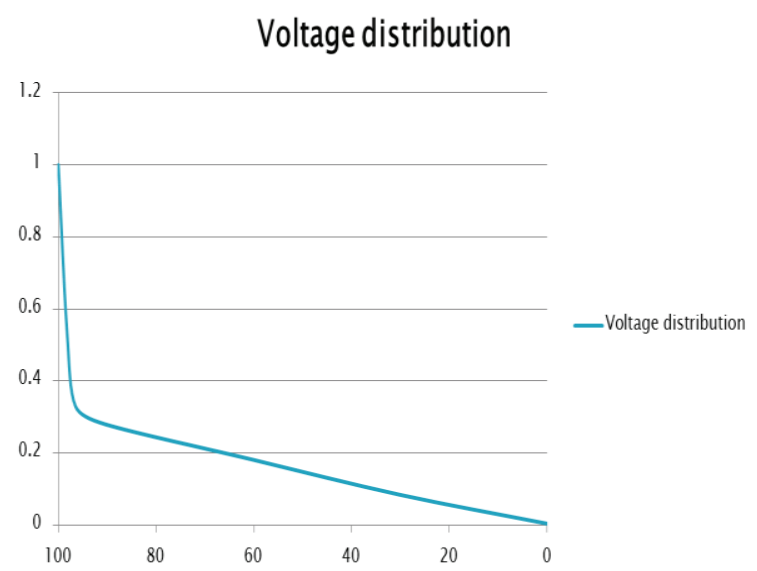

Figure 22 - Initial Impulse Voltage distribution along the HV Winding

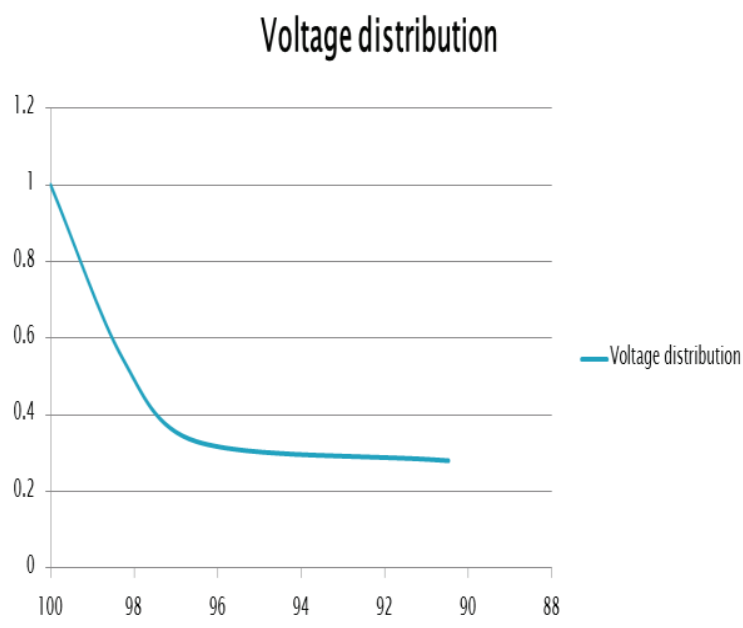

Figure 23 - Initial Impulse Voltage distribution along the outer layers of the $\mathrm{HV}$ Winding

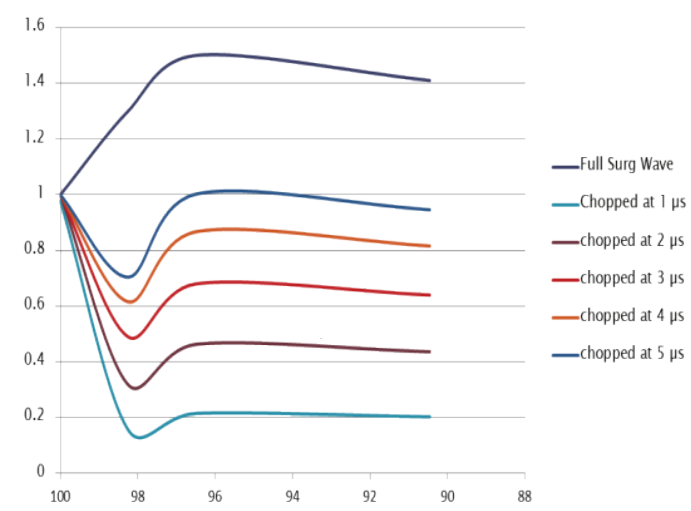

Figure 24 - Impulse Voltage distribution along the outer layers of the HV Winding

\subsection{Sensitivity of the Model}

In order to identify the effect of the individual RLC parameters on the surge voltage distribution along the winding, the simulated output surge waveforms were investigated by increasing and decreasing those parameters by $50 \%$. For the evaluation, the peak value of the first positive cycle, time to first peak, and the peak value of the second positive cycle of the voltage waveforms of $\mathrm{V}_{2}$ and $\mathrm{V}_{3}$ were used. The peak value of the first positive cycle represents the maximum amplitude. The time to first peak provides an idea about the approximate voltage gradient whereas the peak value of the second positive cycle implies the attenuation rate.

Table 3 shows the evaluation results for the $160 \mathrm{kVA}$ transformer together with the variation of their parameters by $50 \%$. 
According to the results, it is clear that the winding resistance $R$ has almost no effect on the surge waveforms $V_{2}$ and $V_{3}$. The winding inductance $\mathrm{L}$ has a huge effect on the time to first peak which is on the approximate voltage gradients of the waveforms. In comparison to other parameters, the inter-layer capacitances $\left(\mathrm{C}_{\mathrm{ll}}\right)$ and the capacitance to ground $\left(\mathrm{C}_{\mathrm{g}}\right)$ affect the output surge waveforms considerably.

Table 3 - Effect of Transformer Parameters on Surge Waveforms

\begin{tabular}{|c|c|c|c|c|c|c|c|}
\hline \multirow{2}{*}{} & \multirow{2}{*}{} & & \multicolumn{2}{|c|}{$1^{\text {st Peak value }}$} & \multicolumn{2}{c|}{$\begin{array}{c}\text { Time to } 1^{\text {st }} \\
\text { peak }(\mu \mathrm{s})\end{array}$} & \multicolumn{2}{c|}{$\begin{array}{c}2^{\text {nd }} \text { Peak } \\
\text { value (pu) }\end{array}$} \\
\cline { 3 - 8 } & & $\mathrm{V}_{2}$ & $\mathrm{~V}_{3}$ & $\mathrm{~V}_{2}$ & $\mathrm{~V}_{3}$ & $\mathrm{~V}_{2}$ & $\mathrm{~V}_{3}$ \\
\hline 1 & $\mathrm{R}, \mathrm{L}, \mathrm{C}$ as it is & $\mathbf{1 . 3 2}$ & $\mathbf{1 . 5 4}$ & $\mathbf{6 . 8 6}$ & 7.57 & $\mathbf{1 . 1 1}$ & $\mathbf{1 . 4 1}$ \\
\hline 2 & $\mathrm{~L}+50 \%$ & 1.30 & 1.52 & 8.20 & 8.99 & 1.06 & 1.36 \\
\hline 3 & $\mathrm{~L}-50 \%$ & 1.34 & 1.56 & 4.97 & 5.36 & 1.17 & 1.47 \\
\hline 4 & $\mathrm{Cll}+50 \%$ & 1.25 & 1.42 & 7.65 & 8.12 & 1.01 & 1.28 \\
\hline 5 & $\mathrm{Cll}-50 \%$ & 1.40 & 1.74 & 5.91 & 6.70 & 1.35 & 1.53 \\
\hline 6 & $\mathrm{Cgt}+50 \%$ & 1.36 & 1.64 & 7.65 & 8.44 & 1.21 & 1.45 \\
\hline 7 & $\mathrm{Cgt}-50 \%$ & 1.22 & 1.36 & 5.99 & 6.23 & 1.03 & 1.03 \\
\hline 8 & $\mathrm{R}+50 \%$ & 1.32 & 1.54 & 6.86 & 7.57 & 1.11 & 1.41 \\
\hline 9 & $\mathrm{R}-50 \%$ & 1.32 & 1.54 & 6.86 & 7.57 & 1.11 & $\begin{array}{c}1.4 \\
1\end{array}$ \\
\hline
\end{tabular}

\section{Conclusion}

In this research, the transient behaviour of a distribution transformer is presented. The methodology to find the transient model of a distribution transformer is given in detail and the parameters have been calculated for a typical $160 \mathrm{kVA}, \quad 33 / 0.415 \mathrm{kV}$ distribution transformer.

The proposed model was validated by comparing the simulated output of the model with an experimental output already observed and presented in a research paper [7]. As shown in Section 3.1, there exists a good correlation between the shape of the surge distribution simulated using PSCAD software and the one measured experimentally [7].

The effect of transformer parameters on the surge voltage distribution along the winding is presented in Section 3.3. The winding inductance (L) has a higher effect on the time to first peak that is on the voltage gradients of the waveforms. The inter-layer capacitances $\left(\mathrm{C}_{11}\right)$ and the capacitance to ground $\left(\mathrm{C}_{\mathrm{g}}\right)$ affect the maximum amplitude, voltage gradient and the attenuation rate of the waveforms. The winding resistance $(\mathrm{R})$ has almost no effect on the surge waveforms.
Initial impulse voltage distribution along the total length of the HV phase winding and that along the length of the two outermost layers of the HV winding are presented in Figures 22 and 23 respectively. These graphs show a higher voltage gradient closer to the line-end of the HV winding. This result explains the reason for the transformer failures that occur due to the failure of the inter-turn insulation of the line-end turns. These graphs can be used to evaluate the initial electrical stresses experienced by the turns of the winding under transient conditions.

\section{References}

[1] Wijekoon, V. B., Wijekoon, H. M. "Measures to Minimize Distribution Transformer Failures in the MV Network of Ceylon electricity Board, Sri Lanka", 2009, 2 p.

[2] Fernando, M. A. R. M., and Cooray, V., "Lightning Surges at Distribution Transformer Secondary", ICIIS 2010, Jul 29Aug 01, India 2010, 3 p.

[3] Luca Dalessandro, Fabiana da Silveira Cavalcante, and Kolar, Johann W., "SelfCapacitance of High-Voltage Transformers", IEEE Transactions on power electronics, vol.22, No.5, September 2007, pp 2-4.

[4] Bjerkan, Eilert "High Frequency Modelling of Power Transformers, Stresses \& Diagonistics", Trondheim, May 2005, pp 2-3.

[5] Marjan Popov, Lou van der Sluis, Rene peter Paul Smeets, and Jose Lopez Roldan, "Analysis of Very Fast Transients in LayerType Transformer Windings", IEEE Transaction on Power Delivery, Vol.22, No.1, January 2007, 2 p.

[6] Popov, M., Smeets, R.P.P., L.van der Sluis, de Herdt , H. and Declercq, J., "Analysis of Voltage Distribution in Transformer Windings During Circuit Breaker Prestrike", International Conference on Power Systems Transients in Kyoto, Japan June 3-6, 2009, 2 p.

[7] Miki, A., Hosoya, T., and Okuyama, K., “A Calculation Method for Impulse Voltage Distribution and Transferred Voltage in Transformer Windings", IEEE Transactions on Power Apparatus and Systems, Vol. PAS-97, no. 3, May/June 1978, 4 p. 
